\title{
Implication of transcriptional repression in compound C-induced apoptosis in cancer cells
}

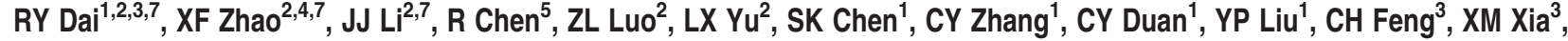 \\ $\mathrm{H} \mathrm{Li}^{1}, \mathrm{~J} \mathrm{Fu}{ }^{\star, 2}$ and $\mathrm{HY}$ Wang ${ }^{\star 2,6}$
}

Compound C, a well-known inhibitor of AMP-activated protein kinase (AMPK), has been reported to induce apoptosis in some types of cells. However, the underlying mechanisms remain largely unclear. Using a DNA microarray analysis, we found that the expression of many genes was downregulated upon treatment with compound C. Importantly, compound C caused transcriptional repression with the induction of p53, a well-known marker of transcriptional stress response, in several cancer cell lines. Compound $C$ did not induce the phosphorylation of p53 but dramatically increased the protein level of p53 similar to some other transcriptional inhibitors, including 5,6-dichloro-1- $\beta$-D-ribobenzimidazole (DRB). Consistent with previous reports, we found that compound $C$ initiated apoptotic death of cancer cells in an AMPK-independent manner. Similar to DRB and actinomycin D (ActD), two classic transcription inhibitors, compound C not only resulted in the loss of Bcl-2 and Bcl-xl protein but also induced the phosphorylation of eukaryotic initiation factor-alpha (elF2 $\alpha$ ) on Ser51. Hence, the phosphorylation of elF2 $\alpha$ might be a novel marker of transcriptional inhibition. It is noteworthy that compound C-mediated apoptosis of cancer cells is correlated with decreased expression of Bcl-2 and Bcl-xl and the phosphorylation of elF $2 \alpha$ on Ser51. Remarkably, compound C exhibits potent anticancer activities in vivo. Taken together, our data suggest that compound $\mathrm{C}$ may be an attractive candidate for anticancer drug development.

Cell Death and Disease (2013) 4, e883; doi:10.1038/cddis.2013.419; published online 24 October 2013

Subject Category: Cancer

Finding therapies that target and kill cancer cells is a major goal of most cancer therapeutic approaches. Several cell death modalities, including programmed cell death, necrosis and mitotic catastrophe can initiate cancer cells death. ${ }^{1-5}$ Irradiation and drugs used for cancer chemotherapy always result in DNA damage and transcriptional stress response, which can lead to apoptotic death, in some cancer cells. ${ }^{4}$

Transcription is an essential process for gene expression in both prokaryotic and eukaryotic cells. Genes coding for proteins in eukaryotes are transcribed by the concerted action of a number of transcription-related factors, chief among them is the RNA polymerase II. ${ }^{6-8}$ With the inhibition of transcription over a certain period of time, cells will be destroyed by apoptosis..$^{9-11}$ It has been shown that DNA-damaging agents and transcriptional inhibitors can induce cell apoptosis in a time-dependent manner. ${ }^{11,12}$ Transcriptional inhibitors are drugs that inhibit global transcription by different mechanisms. Transcriptional inhibitors induce apoptosis partially by inhibiting the expression of labile antiapoptotic proteins because of their ability to downregulate proteins of short half-life. ${ }^{10,13-15}$ The accumulation of p53 is one of the hallmarks of transcriptional stress. ${ }^{11}$ However, transcriptional repression results in apoptosis by both p53-dependent or -independent mechanisms. ${ }^{11}$ Importantly, transformed cells appear to be more sensitive to transcriptional stress induced by disruption of RNA synthesis than normal cells. ${ }^{12,16}$ General transcriptional inhibitors may be useful in cancer therapies and, in some instances, have been shown to work as antiviral agents. ${ }^{13,17}$ Some of these drugs, such as flavopiridol and seliciclib, are potential drugs against different types of cancer. ${ }^{18-23}$

AMP-activated protein kinase (AMPK) is a principal intracellular energy sensor, which has an essential role as a master regulator of cellular energy homeostasis. AMPK is activated by an increasing cellular AMP/ATP ratio caused by metabolic stresses that interfere with ATP production or that accelerate ATP consumption. ${ }^{24-29}$ AMPK maintains the energy balance through the direct phosphorylation of target proteins or via transcriptional control of target genes. ${ }^{30,31}$

\footnotetext{
${ }^{1}$ The Department of Biochemistry and Molecular Biology, Luzhou Medical College, Luzhou, Sichuan 646000, China; ${ }^{2}$ International Cooperation Laboratory on Signal Transduction, Eastern Hepatobiliary Surgery Institute, Second Military Medical University, Shanghai 200438, China; ${ }^{3}$ Department of Hepatobiliary Surgery of the Affiliated Hospital of Luzhou Medical College, Luzhou, Sichuan, China; ${ }^{4}$ Model Animal Research Center and MOE Key Laboratory of Model Animal for Disease Study, Nanjing University, Nanjing, China; ${ }^{5}$ Department of Public Health of Luzhou Medical College, Luzhou, Sichuan, China and ${ }^{6}$ State Key Laboratory of Oncogenes and Related Genes, Cancer Institute of Renji Hospital, Shanghai Jiaotong University, Shanghai 200032, China

${ }^{*}$ Corresponding authors: J Fu or HY Wang, International Cooperation Laboratory on Signal Transduction, Eastern Hepatobiliary Surgery Institute, Second Military Medical University, Shanghai 200438, China. Tel: +86 21 81875361; Fax: +86 21 81875361; E-mails: fujing-724@163.com or hywangk@ vip.sina.com

${ }^{7}$ These authors contributed equally to this work.

Keywords: compound C; transcriptional inhibition; apoptosis; cancer

Abbreviations: AMPK, AMP-activated protein kinase; ActD, actinomycin D; c-Met, hepatocyte growth factor receptor; DRB, 5,6-dichloro-1- $\beta$-D-ribobenzimidazole; EGFR, epidermal growth factor receptor; elF2 $\alpha$, eukaryotic initiation factor-alpha; GRP78, 78 kDa glucose-regulated protein; Tg, thapsigargin; Tun, tunicamycin Received 25.7.13; revised 14.9.13; accepted 17.9.13; Edited by G Raschellá
} 
Compound $\mathrm{C}$, also known as dorsomorphin, has been described as a pharmacological AMPK inhibitor that efficiently blocks metabolic actions of AMPK ${ }^{32}$ It has been reported that compound $\mathrm{C}$ attenuates the apoptotic activities of AMPK in various cell types. ${ }^{33-39}$ In contrast, it has also been suggested that compound $\mathrm{C}$ treatment directly causes apoptosis in some cancer cells, including breast cancer cells and skin cancer cells. ${ }^{40-43}$

In this study, we investigated the potential association between compound $\mathrm{C}$ and apoptosis in different cancer cells. We demonstrated that compound $C$ is a potent apoptosis inducer in various cancer cells. Interestingly, compound C initiates transcriptional inhibition and p53 induction in cancer cells. Further, we found that compound C-mediated apoptosis is associated with the decreased expression of $\mathrm{Bcl}-2$ and $\mathrm{Bcl}-\mathrm{xl}$, and the phosphorylation of elF2 $\alpha$. Importantly, compound $\mathrm{C}$ exhibits potent anticancer activities in vivo.

\section{Results}

Compound $\mathbf{C}$ initiates apoptosis in cancer cells. To investigate the potential role of compound $\mathrm{C}$ in the induction of apoptosis in cancer cells, we first examined the proapoptotic effects of compound C in A549, SMMC-7721 and HeLa cells. Western blot analysis revealed that compound $\mathrm{C}$ treatment induced the cleavage of PARP and caspase-3 in A549, SMMC-7721 and HeLa cells in a concentration-dependent manner (Figure 1a). Moreover, compound $\mathrm{C}$ resulted in the activation of caspase- 3 and PARP cleavage in A549, SMMC-7721 and HeLa cells in a time-dependent manner (Figure 1b). The effects of compound $\mathrm{C}$ on apoptosis induction in cancer cells in a concentration- and time-dependent manner were reconfirmed by annexin V-FITC apoptosis analysis (Figures $1 \mathrm{c}$ and d). Importantly, compound C-mediated apoptosis was obviously inhibited by the pretreatment of z-VAD-fmk, a specific inhibitor of caspase (Figure 1e). Thus, compound $\mathrm{C}$ induces apoptosis in a caspase-dependent manner.

To make sure whether inhibition of AMPK is involved in compound C-mediated apoptosis, specific small-interfering RNA (siRNA) was used to block the expression of MAPK $\alpha$. The results showed that $\mathrm{AMPK} \alpha$ knockdown had no evident effects on compound C-mediated apoptosis in A549, SMMC-7721 and HeLa cells (Supplementary Figure 1). Taken together, these data suggest that compound $C$ initiates apoptosis of cancer cells in an AMPK-independent manner.

Compound $\mathbf{C}$ inhibits transcription in cancer cells. To identify the molecules involved in the proapoptotic activities of compound $\mathrm{C}$, we compared the gene expression profiles of compound C-treated A549 cells with physiological saline-treated A549 cells using microarray analysis. Using a DNA microarray, we analyzed about 32000 genes for changes in expression upon compound $C$ treatment. Statistical analysis indicated that 6030 genes had a significant change in expression levels, of which 5713 (17.85\% of total genes) and 317 ( $0.99 \%$ of total genes) were more than twofold down- or upregulated (Figure 2a). We tested some of the downregulated genes, such as

a

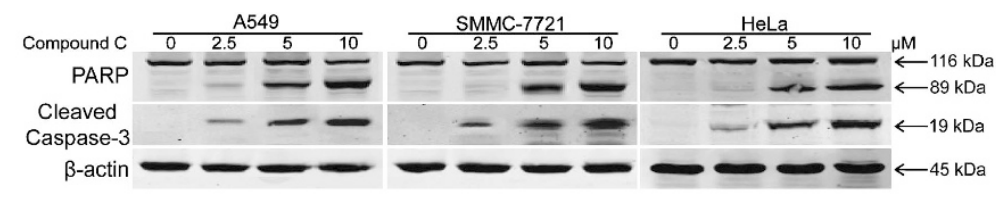

b
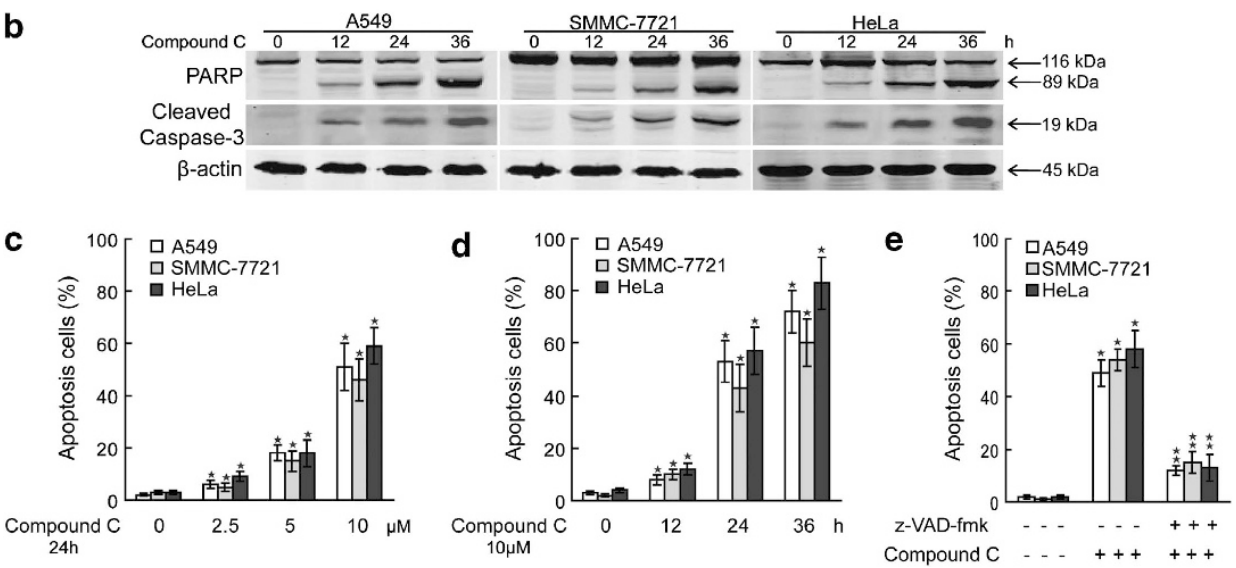

Figure 1 Compound C induces apoptosis. (a) A549, SMMC-7721 and HeLa cells were treated with indicated amounts of compound C for $24 \mathrm{~h}$ and cell lysates were analyzed for the levels of indicated proteins. (b) A549, SMMC-7721 and HeLa cells were treated with $10 \mu \mathrm{mol} / \mathrm{l}$ compound C for indicated periods and cell lysates were analyzed for the levels of indicated proteins. (c) A549, SMMC-7721 and HeLa cells were treated with indicated amounts of compound C for $24 \mathrm{~h}$ and apoptosis were analyzed using flow cytometry after staining with FITC-conjugated Annexin V and propidium iodide. (d) A549, SMMC-7721 and HeLa cells were treated with $10 \mu$ mol/l compound C for indicated periods and apoptosis were analyzed using flow cytometry after staining with FITC-conjugated Annexin V and propidium iodide. (e) A549, SMMC-7721 and HeLa cells were treated with $10 \mu \mathrm{mol} / /$ compound $\mathrm{C}$ for $24 \mathrm{~h}$ with or without z-VAD-fmk (50 $\mu \mathrm{mol} / \mathrm{l})$ pretreatment for $1 \mathrm{~h}$ and apoptosis were analyzed using flow cytometry after staining with FITC-conjugated Annexin V and propidium iodide. Data are presented as mean values \pm S.D. of three measurements. Columns, mean of three individual experiments; bars, S.D. * Significantly different from control value; *^ Significantly different from *value 

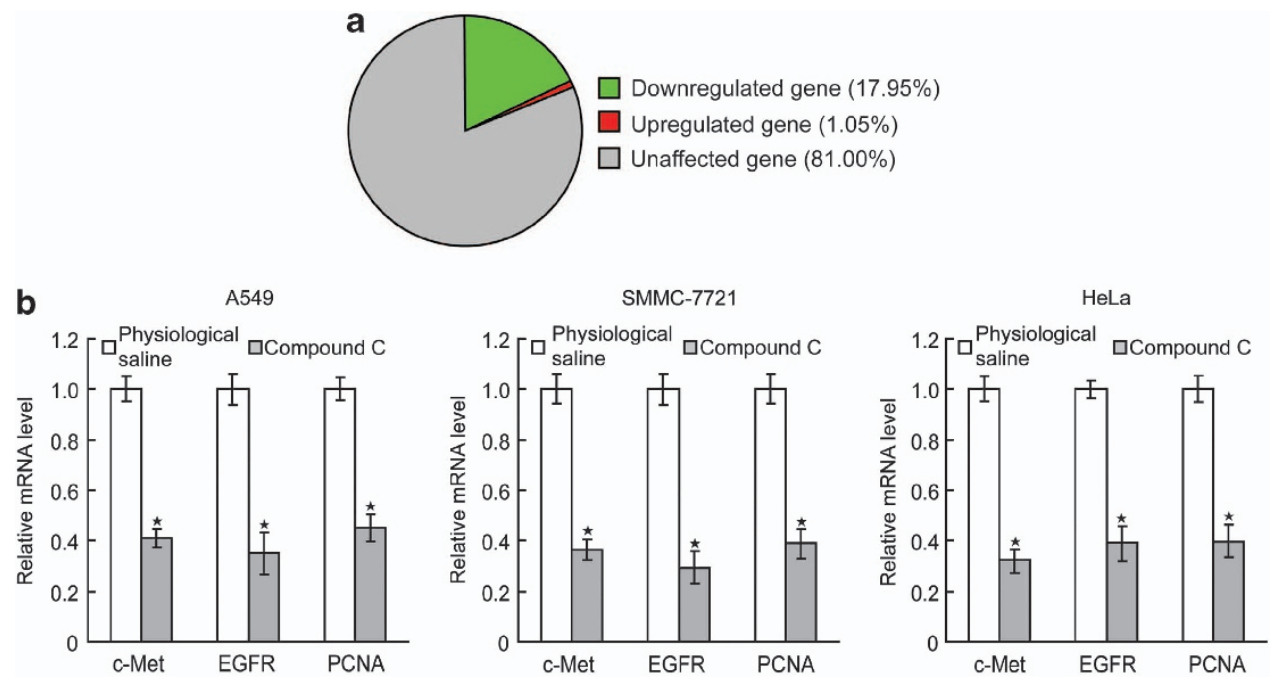

Figure 2 Compound $C$ represses gene expression. (a) A549 cells were treated with $10 \mu \mathrm{mol} / / \mathrm{l}$ compound $\mathrm{C}$ for $24 \mathrm{~h}$ and gene expressions were analyzed using DNA microarray analysis. (b) A549, SMMC-7721 and HeLa cells were treated with $10 \mu \mathrm{mol} / \mathrm{l}$ compound C for $24 \mathrm{~h}$, and c-Met, EGRR and PCNA mRNA levels were analyzed using real-time RT-PCR. Data are presented as mean values \pm S.D. of three measurements. Columns, mean of three individual experiments; bars, S.D. ${ }^{*}$ Significantly different from control value

hepatocyte growth factor receptor (c-Met), epidermal growth factor receptor (EGFR) and proliferating cell nuclear antigen (PCNA), using real-time RT-PCR analysis. The results reconfirmed that c-Met, EGFR and PCNA were downregulated in A549, SMMC-7721 and HeLa cells after compound $\mathrm{C}$ treatment for $24 \mathrm{~h}$ (Figure $2 \mathrm{~b}$ ).

To investigate the impact of compound $\mathrm{C}$ on transcription, mRNA synthesis was measured in compound C-treated cancer cells in the presence of $\left[{ }^{3} \mathrm{H}\right]$ uridine. It is noteworthy that compound $\mathrm{C}$ inhibited mRNA synthesis in a concentrationdependent manner in A549, SMMC-7721 and HeLa cells (Figure $3 a$ ), indicating that compound $\mathrm{C}$ inhibits transcription in cancer cells. As endoplasmic reticulum stress (ER stress) activation can induce the expression of specific mRNA, ${ }^{44-46}$ such as $78 \mathrm{kDa}$ glucose-regulated protein (GRP78) mRNA, the impact of compound C on ER stress-induced GRP78 mRNA synthesis was tested. Importantly, compound $C$ treatment not only decreased GRP78 mRNA but also blocked ER stress inducers tunicamycin (Tun)- and thapsigargin (Tg)-induced GRP78 mRNA synthesis in A549, SMMC-7721 and HeLa cells (Figure $3 b$ ). These results reconfirm the function of transcriptional inhibition of compound $\mathrm{C}$. Further, compound $\mathrm{C}$ induced the downregulation of EGFR mRNA, which is not regulated by ER stress, under ER stress conditions (Figure 3c), suggesting that the effects of compound $\mathrm{C}$ on $\mathrm{ER}$ stress-induced transcription inhibition is nonspecific.

As p53 is one of the hallmarks of global transcriptional repression, ${ }^{10,11,47-49}$ it is reasonable to suggest that compound $\mathrm{C}$ might initiate the induction of p53. This notion is supported by the data that compound $\mathrm{C}$ resulted in the accumulation of p53 in A549, SMMC-7721 and HeLa cells (Figure 3d). In line with DRB, compound C induced the accumulate p53 proteins that lacks evident phosphorylation on Ser15 site (Figure 3e). However, ActD efficiently initiated the phosphorylation of p53 on Ser15 (Figure 3e). Taken together, these data indicate that compound $\mathrm{C}$ is a potent suppressor of transcription.
$\mathrm{Bcl}-2$ and $\mathrm{Bcl}-\mathrm{xl}$ downregulation promotes compound C-induced apoptosis in cancer cells. As transcriptional stress can initiate cell apoptosis in a p53-dependent or p53independent manner, ${ }^{11,50}$ we assessed whether p53 is involved in compound C-mediated apoptosis in cancer cells. It is noteworthy that $\mathrm{p} 53$ inhibitor $\mathrm{PFT}-\alpha$ pretreatment had no demonstrable effects on compound $\mathrm{C}$-mediated apoptosis in A549 and SMMC-7721 cells (Figure 4a). Further, suppression of p53 expression also had no evident effects on compound C-mediated apoptosis (Figure 4b). These data indicate that p53 is not involved in compound C-mediated apoptosis in cancer cells.

As $\mathrm{Bcl}-2$ and $\mathrm{Bcl}-\mathrm{xl}$ are essential for inhibiting the activation of caspases, ${ }^{51-54}$ we investigated whether $\mathrm{Bcl}-2$ and $\mathrm{Bcl}-\mathrm{xl}$ are involved in compound $\mathrm{C}$-mediated apoptosis. The expression of $\mathrm{Bcl}-2$ and $\mathrm{Bcl}-\mathrm{xl}$ in compound $\mathrm{C}$-treated cancer cells was examined. As shown in Figure 5a, compound $\mathrm{C}$ decreased the protein levels of $\mathrm{Bcl}-2$ and $\mathrm{Bcl}-\mathrm{xl}$ in a timedependent manner. More importantly, Bcl-2 and $\mathrm{Bcl}-\mathrm{xl}$ inhibitor ABT-263 preincubation promoted compound C-induced apoptosis in A549, SMMC-7721 and HeLa cells (Figure 5b). Further, transcriptional inhibitors ActD and DRB also induced $\mathrm{Bcl}-2$ and $\mathrm{Bcl}-\mathrm{xl}$ decreasing in A549 and SMMC7721 cells (Figure $5 \mathrm{c}$ ), indicating that the loss of $\mathrm{Bcl}-2$ and $\mathrm{Bcl}-$ $\mathrm{xl}$ promotes transcriptional inhibition-mediated apoptosis. Together, these findings indicate that the compound $\mathrm{C}$-mediated decreasing of $\mathrm{Bcl}-2$ and $\mathrm{Bcl}-\mathrm{xl}$ is involved partially in the apoptosis of cancer cells under compound C-induced transcriptional stress.

The phosphorylation of elF2 $\alpha$ promotes compound C-induced apoptosis in cancer cells. It is known that the elF2 $\alpha$ pathway, a critical pathway that regulates the integrated stress response, can be activated by various stress stimuli. ${ }^{55}$ We therefore studied whether compound C regulates the elF2 $\alpha$ pathway in cancer cells. We found that compound $\mathrm{C}$ induced the phosphorylation of elF2 $\alpha$ on Ser51 
a
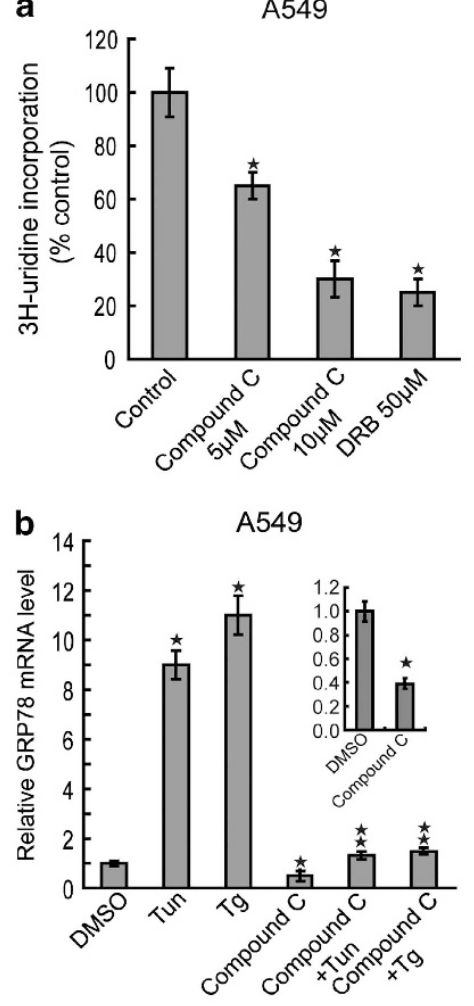

SMMC-7721

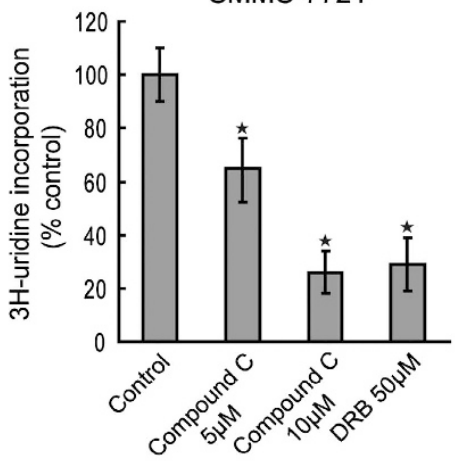

SMMC-7721

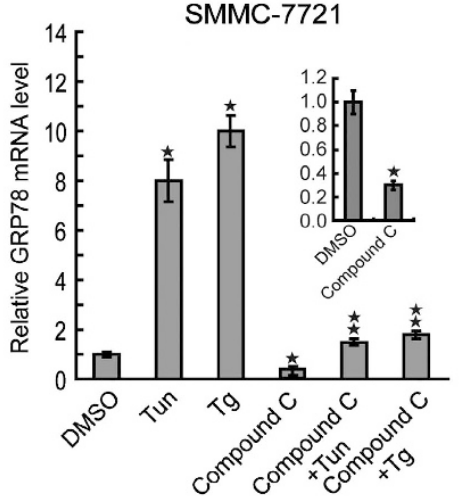

HeLa

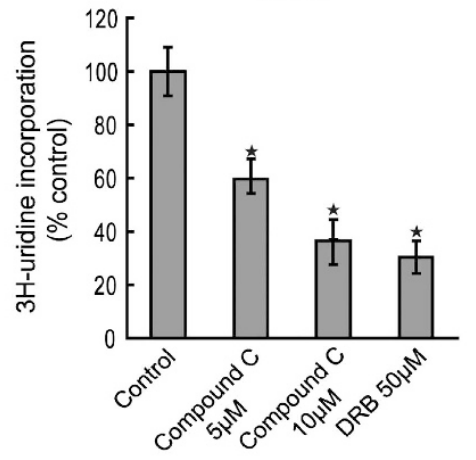

HeLa

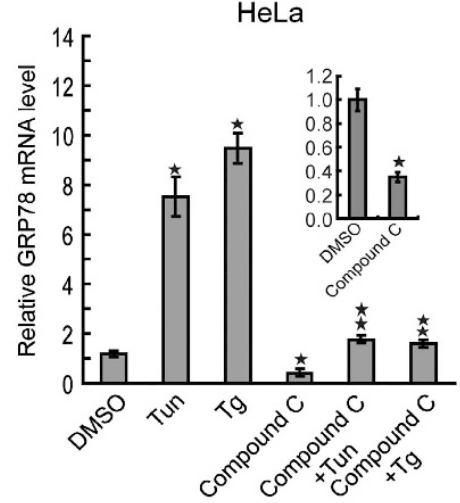

c

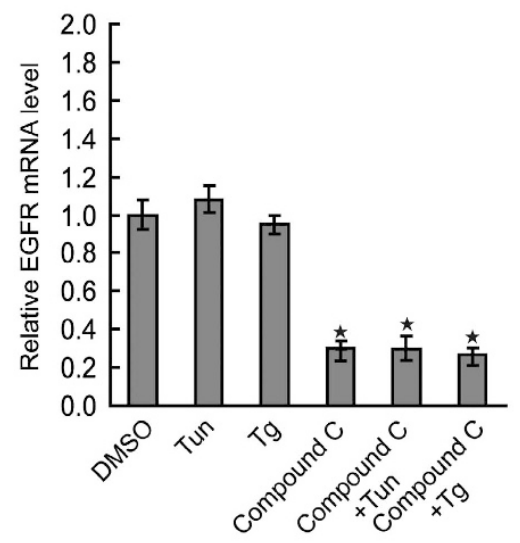

d

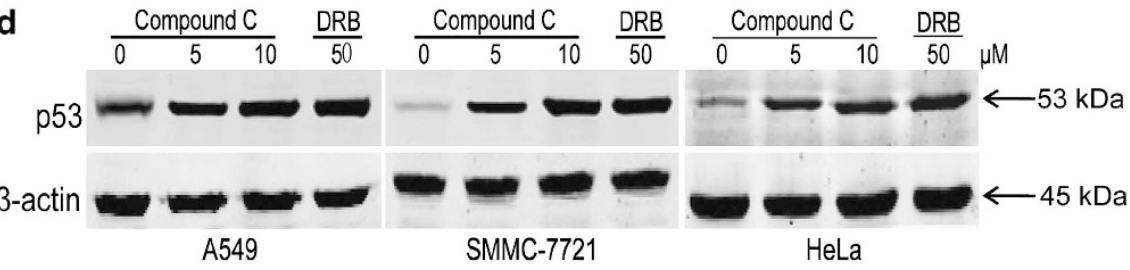

e

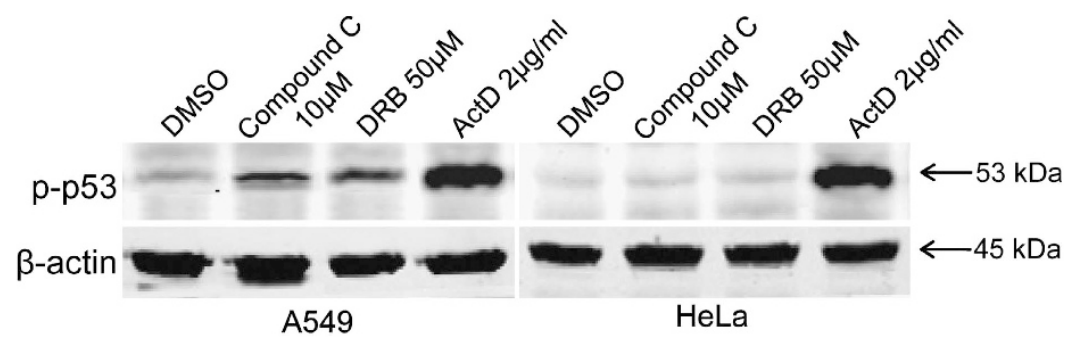

Figure 3 Compound C inhibits transcription. (a) A549, SMMC-7721 and HeLa cells were treated with indicated amounts of compound C or physiological saline for $24 \mathrm{~h}$ in medium containing $0.5 \%$ FBS. The cells were pulsed with $\left[{ }^{3} \mathrm{H}\right]$ thymidine $(1 \mu \mathrm{Ci}$ per well) for $6 \mathrm{~h}$, and then fixed with $5 \%$ trichloroacetic acid and solubilized before scintillation counting. DRB was used as the positive control. (b) A549, SMMC-7721 and HeLa cells were treated with $2.5 \mu \mathrm{g} / \mathrm{ml}$ tunicamycin (Tun) or $1 \mu$ mol/l thapsigargin (Tg) for $12 \mathrm{~h}$ with or without $10 \mu \mathrm{mol} / /$ compound C pretreatment for $1 \mathrm{~h}$, and GRP78 mRNA levels were analyzed using real-time RT-PCR. (c) A549 cells were treated with $2.5 \mu \mathrm{g} / \mathrm{ml}$ Tun or $1 \mu \mathrm{mol} / \mathrm{I} \mathrm{Tg}$ for $12 \mathrm{~h}$ with or without $10 \mu \mathrm{mol} / /$ compound $\mathrm{C}$ pretreatment for $1 \mathrm{~h}$, and EGFR mRNA levels were analyzed using real-time RT-PCR. (d) A549, SMMC-7721 and HeLa cells were treated with indicated amounts of compound $\mathrm{C}$ for $24 \mathrm{~h}$ and cell lysates were analyzed for the levels of indicated proteins. DRB was used as the positive control. (e) A549 and HeLa cells were treated with $10 \mu \mathrm{mol} / \mathrm{l}$ of compound C for $24 \mathrm{~h}$ and cell lysates were analyzed for the levels of indicated proteins. DRB was used as the negative control and ActD was used as the positive control. Data are presented as mean values \pm S.D. of three measurements. Columns, mean of three individual experiments; bars, S.D. * Significantly different from control value; ** Significantly different from *value

in a dose- and time-dependent manner (Figures $6 a$ and b), indicating the elF2 $\alpha$ pathway is implicated in compound C-induced transcriptional stress response. To further test the role of the elF2 $\alpha$ pathway in transcriptional stress response, we investigated the phosphorylation of elF2 $\alpha$ on Ser51 upon ActD or DRB treatment. The data showed that ActD and DRB induced the phosphorylation of elF2 $\alpha$ on Ser51 in A549, SMMC-7721 and HeLa cells (Figure 6c), indicating that transcriptional stress activates the elF2 $\alpha$ pathway.

To make sure whether the phosphorylation of elF2 $\alpha$ has a role in compound C-induced apoptosis, salubrinal, a selective inhibitor of elF2 $\alpha$ dephosphorylation, was used in our study. 


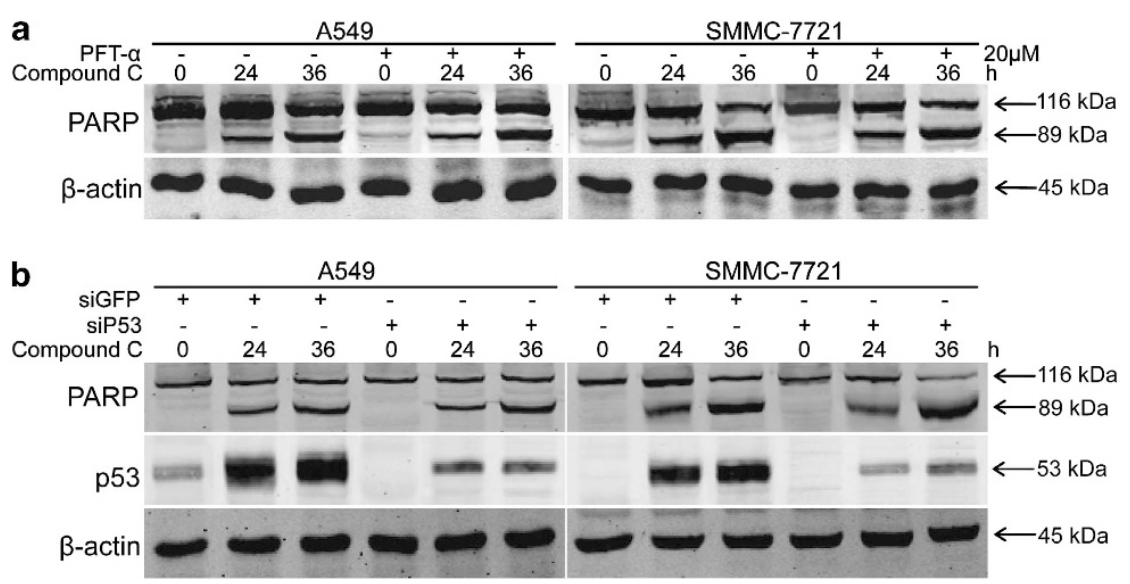

Figure 4 The induction of p53 is not involved in compound C-induced apoptosis. (a) A549 and SMMC-7721 cells were treated with $10 \mu \mathrm{mol} / \mathrm{l}$ compound C for indicated periods with or without PFT- $\alpha(20 \mu \mathrm{mol} / \mathrm{l})$ pretreatment for $1 \mathrm{~h}$ and cell lysates were analyzed for the levels of indicated proteins. (b) After GFP or P53 siRNAs transient transfection for $48 \mathrm{~h}$, A549 and SMMC-7721 cells were treated with $10 \mu \mathrm{mol} / \mathrm{l}$ compound C for indicated periods and cell lysates were analyzed for the levels of indicated proteins

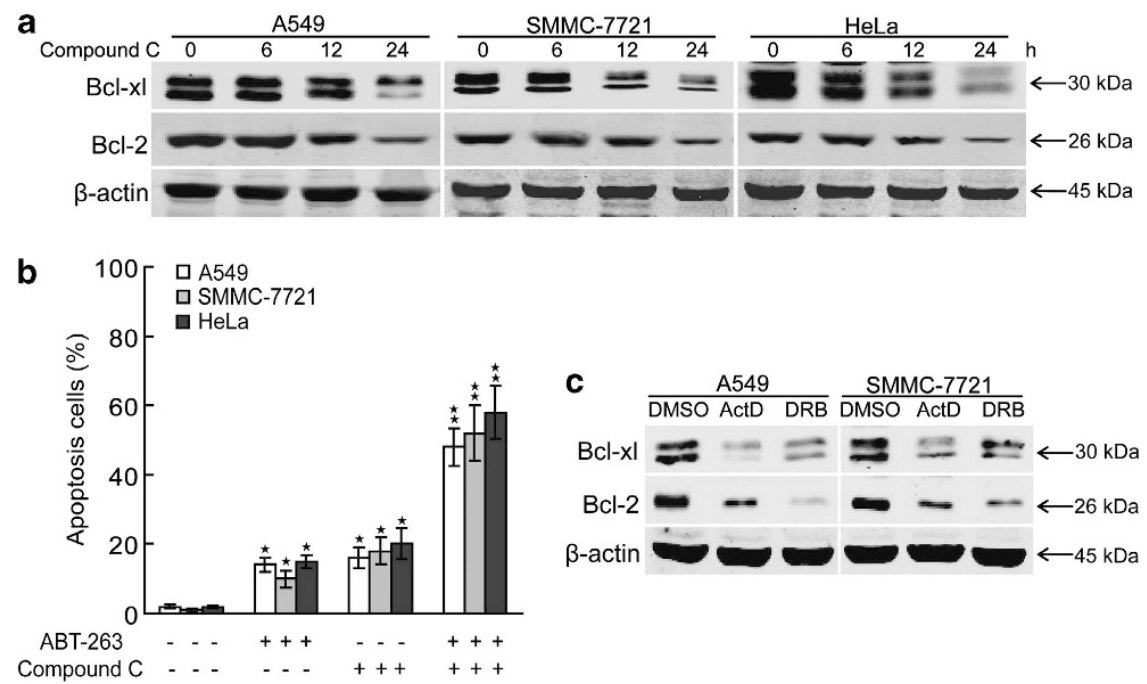

Figure 5 The downregulation of Bcl-2 and Bcl-xl promotes compound C-induced apoptosis. (a) A549, SMMC-7721 and HeLa cells were treated with $10 \mu$ mol// compound $\mathrm{C}$ for indicated periods and cell lysates were analyzed for the levels of indicated proteins. (b) A549, SMMC-7721 and HeLa cells were treated with $5 \mu$ mol/l compound C for $24 \mathrm{~h}$ with or without ABT-263 $(1 \mu \mathrm{mol} / \mathrm{l})$ pretreatment for $1 \mathrm{~h}$, and apoptosis were analyzed using flow cytometry after staining with FITC-conjugated Annexin $\mathrm{V}$ and propidium iodide. (c) A549 and SMMC-7721 cells were treated with $10 \mu \mathrm{g} / \mathrm{ml} \mathrm{ActD}$ or $50 \mu \mathrm{mol} / \mathrm{l}$ DRB for $24 \mathrm{~h}$ and cell lysates were analyzed for the levels of indicated proteins. Data are presented as mean values \pm S.D. of three measurements. Columns, mean of three individual experiments; bars, S.D. * Significantly different from control value; ${ }^{* *}$ Significantly different from *value

As depicted in Figure 6d, salubrinal pretreatment promoted A549, SMMC-7721 and HeLa cells apoptosis upon compound C treatment. Further, transfection of A549, SMMC-7721 and HeLa cells with the phosphorylation-mutant expression plasmid elF2 $\alpha$ S51A, which inhibits the phosphorylation of elF2 $\alpha$ on Ser51, inhibited compound C-mediated apoptosis (Figure 6e). Taken together, these results suggest the phosphorylation of elF2 $\alpha$ is involved in part in the apoptosis of cancer cells under compound C-mediated transcriptional stress.

Compound $\mathbf{C}$ suppresses growth of cancer cells in mice. We assessed the potential of compound $C$ in inhibition of tumor formation using an in vivo mouse model. The subcutaneous tumor model was chosen in our experiments for its high implant survival rate and ease in separating tumor from host tissue for accurate measurements of tumor growth. Treatment with compound $C$ significantly reduced tumor burden of A549 and SMMC-7721 cells as compared with the control group (Figures $7 \mathrm{a}$ and $\mathrm{b}$ ). These data demonstrated that compound $\mathrm{C}$ suppresses the growth of cancer cells in xenograft mouse models, which imply a potential use of compound $\mathrm{C}$ in repressing the progression of cancer cells.

\section{Discussion}

Although compound $\mathrm{C}$ is implicated in the induction of apoptosis, it remains largely unclear how compound $C$ exerts its proapoptotic action. ${ }^{40-43}$ The present work reveals that compound $\mathrm{C}$ represses transcription and initiates apoptosis in 


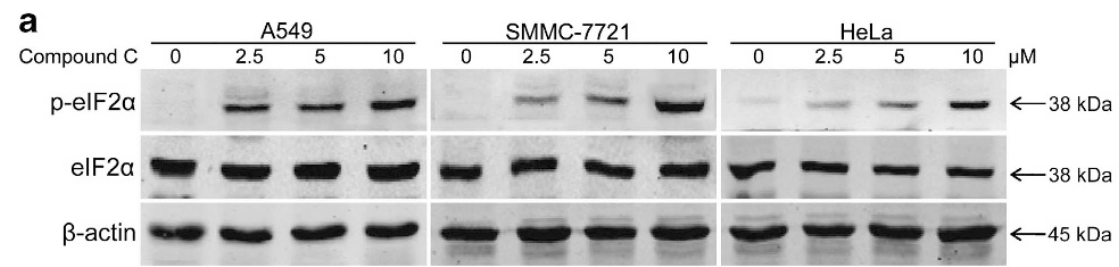

b

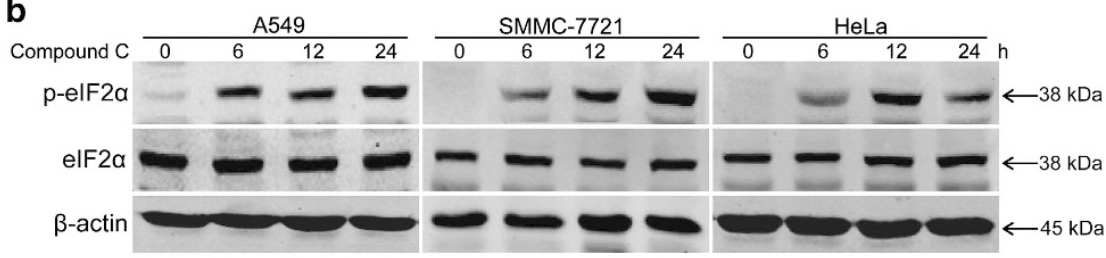

C

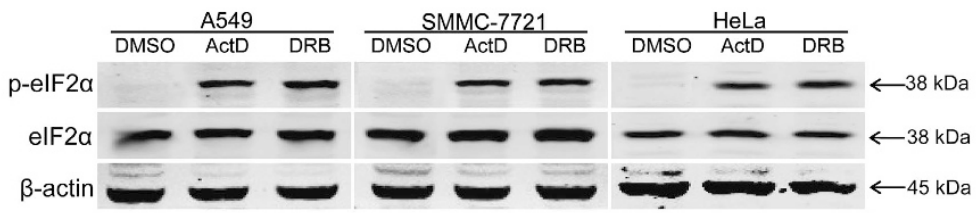

d

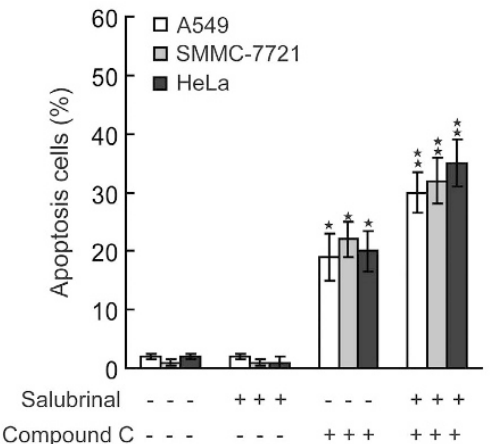

e

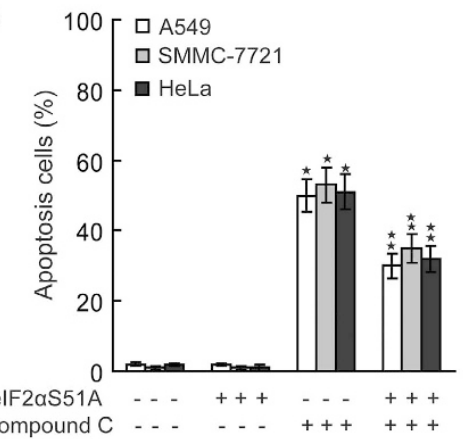

Figure 6 The phosphorylation of elF2 $\alpha$ promotes compound C-induced apoptosis. (a) A549, SMMC-7721 and HeLa cells were treated with indicated amounts of compound C for $24 \mathrm{~h}$ and cell lysates were analyzed for the levels of indicated proteins. (b) A549, SMMC-7721 and HeLa cells were treated with $10 \mu$ mol/I compound C for indicated periods and cell lysates were analyzed for the levels of indicated proteins. (c) A549, SMMC-7721 and HeLa cells were treated with $10 \mu \mathrm{g} / \mathrm{ml}$ ActD or $50 \mu \mathrm{mol} / / \mathrm{DRB}$ for $12 \mathrm{~h}$ and cell lysates were analyzed for the levels of indicated proteins. (d) A549, SMMC-7721 and HeLa cells were treated with $10 \mu$ mol/l compound C for $20 \mathrm{~h}$ with or without salubrinal $(25 \mu \mathrm{mol} / \mathrm{l})$ pretreatment for $1 \mathrm{~h}$, and apoptosis were analyzed using flow cytometry after staining with FITC-conjugated Annexin $\mathrm{V}$ and propidium iodide. (e) After elF2 $\alpha$ S51A expression plasmids transient transfection for $24 \mathrm{~h}, \mathrm{~A} 549$, SMMC-7721 and HeLa cells were treated with $10 \mu$ mol/l compound C for $24 \mathrm{~h}$, and apoptosis were analyzed using flow cytometry after staining with FITC-conjugated Annexin $V$ and propidium iodide. Data are presented as mean values \pm S.D. of three measurements. Columns, mean of three individual experiments; bars, S.D. * Significantly different from control value; ** Significantly different from *value

cancer cells partially by decreasing the expression of $\mathrm{Bcl}-2$ and $\mathrm{Bcl}-\mathrm{xl}$, and by inducing the phosphorylation of elF2 $\alpha$.

It has been suggested that compound $\mathrm{C}$ induces apoptosis in some types of cells. ${ }^{40-43}$ In agreement with these reports, we saw a similar effect in several cancer cell lines upon treatment with compound $\mathrm{C}$. On the basis of the data that blocking AMPK $\alpha$ had no effects on compound C-induced apoptosis, we suggest compound $C$ induces apoptosis in an AMPK-independent manner in cancer cells. As compound C induces autophagy through AMPK inhibition-independent mechanisms, ${ }^{56}$ it is necessary to address whether the induction of autophagy is involved in apoptosis of cancer cells upon compound $\mathrm{C}$ treatment. Compound $\mathrm{C}$ induced autophagy in A549 and HeLa cells (Supplementary Figure 2a), but the activation of autophagy was not responsible for compound C-mediated apoptosis (Supplementary Figure 2b). Apoptosis in mammalian cells is a multistep process that results in the activation of caspases, followed by execution of cell death. We found that compound $\mathrm{C}$-induced apoptosis is caspase dependent.

A noteworthy property of compound $C$ is its ability to inhibit transcription in various cancer cells. A recent report indicated that compound $\mathrm{C}$ inhibits ER stress-induced transcription program depending on the glucose deprivation conditions through a mechanism independent of AMPK. ${ }^{57}$ However, our data indicate that compound $\mathrm{C}$ blocks ER stress-induced transcription through nonspecific transcriptional blockade. A striking feature of compound C-mediated apoptosis is that it is p53 independent. We have shown that A549, SMMC-7721 and HeLa cells along with their p53 inhibition or knockdown undergo apoptosis to the same extent upon treatment with compound $\mathrm{C}$. This is in agreement with the observation that p53 is a marker but not a mediator of transcriptional inhibitors ARC- and flavopiridol-induced apoptosis. ${ }^{10,48}$ However, some 
a

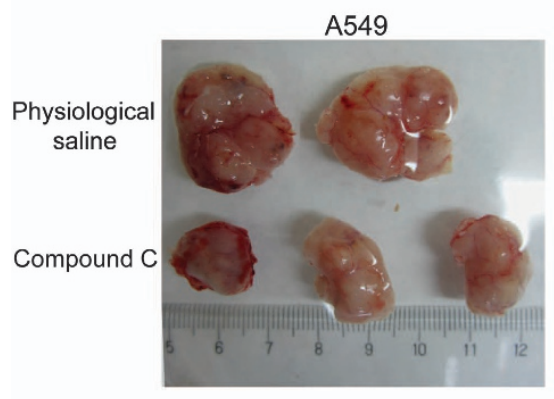

b

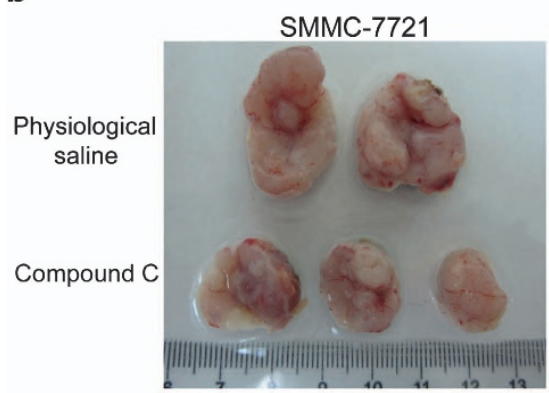

A549

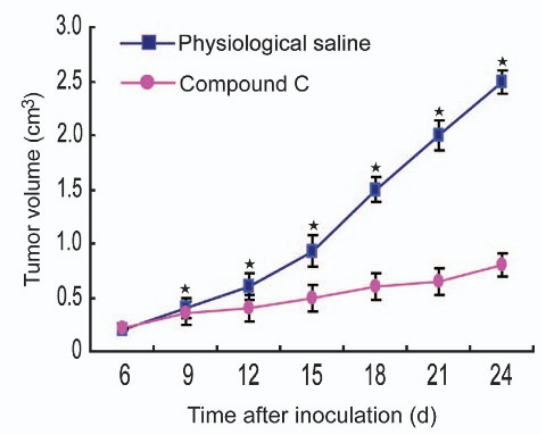

SMMC-7721

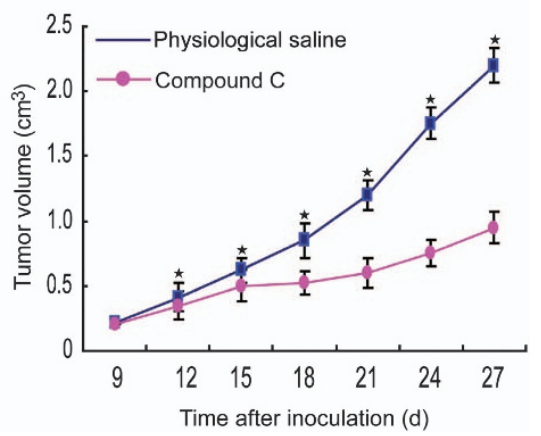

Figure 7 Compound C suppresses growth of cancer cells in mice. (a and b) After mice were subcutaneously inoculated with $1 \times 10^{7}$ A549 (a) or SMMC-7721 (b) cells for 7 days, intratumoral injection was performed to the experimental group mice with $15 \mathrm{mg} / \mathrm{kg}$ compound $\mathrm{C}$ twice weekly. The control group mice were treated by direct intratumoral injection of physiological saline twice weekly. Representative subcutaneous tumors are shown (left panel). Tumor size was measured every 3 days from day 6 (a) or 9 (b) through days 24 (a) or 27 (b) after inoculation of A549 (a) or SMMC-7721 (b) cells into mice (right panel). Error bars stand for S.D. of six animals

of other transcriptional inhibitors, such as DRB and $\alpha$-amanitin, were suggested to induce p53-dependent apoptosis. ${ }^{47,58}$ It was shown recently that p53 knockdown cancer cells were much more resistant to compound C-induced apoptosis. $^{42}$ In our study, however, although the accumulation of p53 was observed in response to compound $\mathrm{C}$ treatment, it did not lead to enhanced apoptosis. The reason for this discrepancy is unclear. The differences in the cell lines or experimental approaches used in studies could be the reason behind the difference in outcome.

An important question now before us is how compound $\mathrm{C}$ induces apoptosis under transcription stress conditions. On the basis of our findings that compound $C$ resulted in $\mathrm{Bcl}-2$ and $\mathrm{Bcl}-\mathrm{xl}$ decrease, we propose that $\mathrm{Bcl}-2$ and $\mathrm{Bcl}-\mathrm{xl}$ might be involved in compound C-mediated apoptosis. This speculation was demonstrated by the findings that blocking the function of $\mathrm{Bcl}-2$ and $\mathrm{Bcl}-\mathrm{xl}$ promoted compound C-induced apoptosis. In our case, it is reasonable to speculate that the ability of compound $\mathrm{C}$ to downregulate antiapoptotic proteins, including $\mathrm{Bcl}-2$ and $\mathrm{Bcl}-\mathrm{xl}$, has an important role in transcription repression-induced apoptosis upon treatment with compound C.

As compound $\mathrm{C}$ induced the phosphorylation on Ser51 of elF $2 \alpha$, which is an important regulator of the decision between survival and apoptosis in response to diverse stress, ${ }^{55}$ we focused on the role of elF $2 \alpha$ signaling in regulating compound C-mediated apoptosis. As salubrinal, the selective inhibitor of elF $2 \alpha$ dephosphorylation, pretreatment promoted cancer cells apoptosis upon compound $\mathrm{C}$ treatment, it is reasonable to suggest that the phosphorylation of elF $2 \alpha$ contributed to compound C-induced apoptosis. This is further supported by the observation that blocking the phosphorylation of elF $2 \alpha$ by the phosphorylation-mutant expression plasmid elF2 $\alpha$ S51A inhibited compound C-induced apoptosis. Interestingly, other transcriptional inhibitors, including ActD and DRB, also induced the phosphorylation of elF2 $\alpha$ on Ser51, indicating that the elF2 $\alpha$ pathway is an important regulator of transcriptional stress. The fact that compound $\mathrm{C}$ repressed tumor growth in mice models makes a strong case for consideration of compound $\mathrm{C}$ as a potential antitumor agent. Hence, compound $\mathrm{C}$ could be a promising candidate for in vivo studies.

In brief, the present work reveals that transcriptional repression has an essential role in compound $\mathrm{C}$-induced apoptosis in cancer cells. The ability of compound $\mathrm{C}$ to inhibit tumor growth in vivo implies its potent anticancer activities. More detailed studies on the function of compound $C$ upon transcriptional repression will contribute to the development of compound $\mathrm{C}$ as anticancer drug.

\section{Materials and Methods}

Chemicals and antibodies. AMPK inhibitor compound C, elF2 $\alpha$ phosphatase enzymes inhibitor salubrinal and autophagy inhibitor bafilomycin $A 1$ were purchased from Tocris Bioscience (Bristol, UK). Transcriptional inhibitors DRB and ActD, p53 inhibitor PFT- $\alpha$, caspase inhibitor z-VAD-fmk and ER stress inducers Tg and Tun were purchased from Sigma (Lyon, France). Bcl-2 and Bcl-xl inhibitor ABT-263 was purchased from Selleck Chemicals (Houston, TX, USA). GFP siRNA, p53 siRNA, AMPK $\alpha$ siRNA and antibodies against elF2 $\alpha$ and $\beta$-actin were purchased from Santa Cruz Biotechnology (Heidelberg, Germany). Antibodies 
against phospho-elF2 $\alpha$ (Ser51), phospho-p53 (Ser15), AMPK $\alpha$, p53, Bcl-2, Bcl-xl, PARP, cleaved caspase-3 and LC3A/B were purchased from Cell Signaling Technology (Danvers, MA, USA). elF2 $\alpha$ S51A plasmid was purchased from Addgene (Cambridge, MA, USA).

Cell culture and treatments. Human lung adenocarcinoma epithelial cell line A549, human hepatocellular carcinoma cell line SMMC-7721 and human cervical cancer cell line HeLa were cultured in Dulbecco's modified Eagle's medium supplemented with $10 \%$ fetal bovine serum and $1 \%$ penicillin/ streptomycin in a humidified incubator containing $5 \% \mathrm{CO}_{2}$ and $95 \%$ ambient air at $37^{\circ} \mathrm{C}$. The protocol used for p53 and AMPK $\alpha$ knockdown has been previously described. ${ }^{59}$ Transfection of vectors for the expression of GFP and elF2 $\alpha$ S51A, which lacks the phosphorylation site, were performed using Lipofectamine 2000 (Invitrogen, Carlsbad, CA, USA) according to the manufacturer's manual.

Western blot analysis. Cells were lysed in Triton lysis buffer $(20 \mathrm{mM}$ Tris, pH 7.4, $137 \mathrm{mM} \mathrm{NaCl}, 10 \%$ glycerol, $1 \%$ Triton X-100, 2 mM EDTA, 1 mM PMSF, $10 \mathrm{mM}$ sodium fluoride, $5 \mathrm{mg} / \mathrm{ml}$ of aprotinin, $20 \mathrm{mM}$ leupeptin and $1 \mathrm{mM}$ sodium orthovanadate) and centrifuged at $12000 \times g$ for $15 \mathrm{~min}$. Protein concentrations were measured using the BCA assay. Protein samples were denatured with $4 \times$ SDS-loading buffer $(200 \mathrm{mM}$ Tris, $\mathrm{pH} 6.8,8 \%$ SDS, $400 \mathrm{mM} \mathrm{DTT}, 0.4 \%$ bromphenol blue and $40 \%$ glycerol) at $100^{\circ} \mathrm{C}$ for $5 \mathrm{~min}$ and subjected to standard SDS-PAGE and western blot analysis as previously described. ${ }^{60}$

Apoptosis analysis. Apoptosis was detected using the annexin V-FITC apoptosis detection kit (Invitrogen) according to the manufacturer's manual. Annexin $V$ staining was analyzed by flow cytometry within $1 \mathrm{~h}$. The experiments were repeated three times.

Reverse transcription reaction and real-time PCR. Total RNA was isolated with TRIzol reagent (Invitrogen) according to the manufacturer's instructions. The reverse transcription reactions were carried out using the M-MLV reverse transcriptase (Promega, Madison, WI, USA) according to the manufacturer's protocol. Real-time PCR analyses were performed using SYBR Premix Ex Taq (TaKaRa, Tokyo, Japan). Results were normalized with 18S. The primers used in this study are shown in Supplementary Table 1.

Thymidine incorporation. Cells $\left(1-2 \times 10^{4}\right.$ per well) were grown overnight in 24-well plates and treated with $10 \mu \mathrm{M} / \mathrm{l}$ compound $\mathrm{C}$ for the experimental wells or physiological saline for the control wells in medium containing $0.5 \%$ FBS. After $24 \mathrm{~h}$, the cells were pulsed with $\left[{ }^{3} \mathrm{H}\right]$ thymidine $(1 \mu \mathrm{Ci}$ per well) for $6 \mathrm{~h}$, and then fixed with $5 \%$ trichloroacetic acid and solubilized before scintillation counting. Experiments were repeated three times.

RNA isolation and microarray analysis. Total RNA was extracted from cells using the RNeasy Mini kit (Qiagen, Valencia, CA, USA) according to the manufacturer's protocol. Fluorescent aRNA targets were prepared from $2.5 \mu \mathrm{g}$ total RNA samples using OneArray Amino Allyl aRNA Amplification Kit (Phalanx Biotech Group, Hsinchu, Taiwan) and Cy5 dyes (Amersham Pharmacia, Piscataway, NJ, USA). Fluorescent targets were hybridized to the Human Whole Genome OneArray with Phalanx hybridization buffer using Phalanx Hybridization System. After $16 \mathrm{~h}$ hybridization at $50^{\circ} \mathrm{C}$, nonspecific binding targets were washed away by three different washing steps (wash I, $42{ }^{\circ} \mathrm{C}$ for $5 \mathrm{~min}$; Wash $I I, 42^{\circ} \mathrm{C}$ for $5 \mathrm{~min}, 25^{\circ} \mathrm{C}$ for $5 \mathrm{~min}$; Wash III, rinse 20 times) and the slides were dried by centrifugation and scanned by Axon 4000B scanner (Molecular Devices, Sunnyvale, CA, USA). The intensities of each probe were obtained by GenePix 4.1 software (Molecular Devices).

Tumor xenograft experiments. The use of animals in present study has been approved by the local committee on animal care. Six-week-old NOD/SCID nude mice were purchased from the Shanghai Experimental Center (CSA, Shanghai, China). Mice were subcutaneously inoculated with A549 or SMMC7721 cells. Approximately $1 \times 10^{7}$ cells in $0.2 \mathrm{ml}$ culture medium containing phosphate-buffered saline were injected subcutaneously into the right flank of the mice, which were then observed daily for signs of tumor development. Tumor volume was calculated as below: $V\left(\mathrm{~cm}^{3}\right)=$ width $^{2}\left(\mathrm{~cm}^{2}\right) \times$ length $(\mathrm{cm}) / 2$. Seven days after inoculation, mice were randomly divided into two groups $(n=6)$. Intratumoral injection was performed to the experimental group mice with $15 \mathrm{mg} / \mathrm{kg}$ compound C (compound C were dissolved in physiological saline) twice weekly.
The control group mice were treated by direct intratumoral injection of physiological saline twice weekly.

Immunofluorescence staining and confocal microscopy analysis. Cells were replated on chamber slides. When cultured to $60 \%$ confluence, cells that were incubated with anti-LC3A/B antibodies conjugated to CY3 (Invitrogen) for immunofluorescence and confocal microscopy assay.

Statistical analysis. Results were expressed as the mean \pm S.D. Statistical analysis was performed using Student's t-test. $P<0.05$ was considered statistically significant.

\section{Conflict of Interest}

The authors declare no conflict of interest.

Acknowledgements. This work was supported by grants from Sichuan Province Science Foundation for Youths (2013JQ0045), the National Natural Science Foundation of China (81000886, 81221061, 81101714, 91029732, 91229201), New Century Excellent Talents in University Grant (NCET-11-1058), State Key Project for Infectious Diseases (2012ZX10002-009, 011), and Key Project of Army (BWS11J030).

1. Brown JM, Attardi LD. The role of apoptosis in cancer development and treatment response. Nat Rev Cancer 2005; 5: 231-237.

2. Sauter B, Albert ML, Francisco L, Larsson M, Somersan S, Bhardwaj N. Consequences of cell death: exposure to necrotic tumor cells, but not primary tissue cells or apoptotic cells, induces the maturation of immunostimulatory dendritic cells. J Exp Med 2000; 191: 423-434.

3. Amaravadi RK, Thompson CB. The roles of therapy-induced autophagy and necrosis in cancer treatment. Clin Cancer Res 2007; 13: 7271-7279.

4. Edinger AL, Thompson CB. Death by design: apoptosis, necrosis and autophagy. Curr Opin Cell Biol 2004; 16: 663-669.

5. Kono K, Mimura K, Kiessling R. Immunogenic tumor cell death induced by chemoradiotherapy: molecular mechanisms and a clinical translation. Cell Death Dis 2013; 4: e688.

6. Berger I, Blanco AG, Boelens R, Cavarelli J, Coll M, Folkers GE et al. Structural insights into transcription complexes. J Struct Biol 2011; 175: 135-146.

7. Kornberg RD. The molecular basis of eucaryotic transcription. Cell Death Differ 2007; 14: 1989-1997.

8. Boeger H, Bushnell DA, Davis R, Griesenbeck J, Lorch Y, Strattan JS et al. Structural basis of eukaryotic gene transcription. FEBS Lett 2005; 579: 899-903.

9. Chen R, Keating MJ, Gandhi V, Plunkett W. Transcription inhibition by flavopiridol: mechanism of chronic lymphocytic leukemia cell death. Blood 2005; 106: 2513-2519.

10. Radhakrishnan SK, Gartel AL. A novel transcriptional inhibitor induces apoptosis in tumor cells and exhibits antiangiogenic activity. Cancer Res 2006; 66: 3264-3270.

11. Gartel AL. Transcriptional inhibitors, p53 and apoptoss. Biochim Biophys Acta 2008; 1786 83-86.

12. Derheimer FA, Chang CW, Ljungman M. Transcription inhibition: a potential strategy for cancer therapeutics. Eur J Cancer 2005; 41: 2569-2576.

13. Blagosklonny MV. Flavopiridol, an inhibitor of transcription: implications, problems and solutions. Cell Cycle 2004; 3: 1537-1542.

14. Radhakrishnan SK, Halasi M, Bhat UG, Kurmasheva RT, Houghton PJ, Gartel AL. Proapoptotic compound ARC targets Akt and N-myc in neuroblastoma cells. Oncogene 2008; 27: 694-699.

15. Rosato RR, Almenara JA, Kolla SS, Maggio SC, Coe S, Gimenez MS et al. Mechanism and functional role of XIAP and $\mathrm{Mcl}-1$ down-regulation in flavopiridol/vorinostat antileukemic interactions. Mol Cancer Ther 2007; 6: 692-702.

16. Koumenis C, Giaccia A. Transformed cells require continuous activity of RNA polymerase II to resist oncogene-induced apoptosis. Mol Cell Biol 1997; 17: 7306-7316.

17. Chao SH, Fujinaga K, Marion JE, Taube R, Sausville EA, Senderowicz AM et al. Flavopiridol inhibits P-TEFb and blocks HIV-1 replication. J Biol Chem 2000; 275: 28345-28348.

18. Shapiro Gl. Cyclin-dependent kinase pathways as targets for cancer treatment. J Clin Oncol 2006; 24: 1770-1783.

19. Benson C, White J, De Bono J, O'Donnell A, Raynaud F, Cruickshank C et al. A phase I trial of the selective oral cyclin-dependent kinase inhibitor seliciclib (CYC202; R-Roscovitine), administered twice daily for 7 days every 21 days. Br J Cancer 2007; 96: 29-37.

20. Lin TS, Ruppert AS, Johnson AJ, Fischer B, Heerema NA, Andritsos LA et al. Phase II study of flavopiridol in relapsed chronic lymphocytic leukemia demonstrating high response rates in genetically high-risk disease. J Clin Oncol 2009; 27: 6012-6018. 
21. Dispenzieri A, Gertz MA, Lacy MQ, Geyer SM, Fitch TR, Fenton RG et al. Flavopiridol in patients with relapsed or refractory multiple myeloma: a phase 2 trial with clinical and pharmacodynamic end-points. Haematologica 2006; 91: 390-393.

22. MacCallum DE, Melville J, Frame S, Watt K, Anderson S, Gianella-Borradori A et al. Seliciclib (CYC202, R-Roscovitine) induces cell death in multiple myeloma cells by inhibition of RNA polymerase II-dependent transcription and down-regulation of Mcl-1. Cancer Res 2005; 65: 5399-5407.

23. Byrd JC, Lin TS, Dalton JT, Wu D, Phelps MA, Fischer B et al. Flavopiridol administered using a pharmacologically derived schedule is associated with marked clinical efficacy in refractory, genetically high-risk chronic lymphocytic leukemia. Blood 2007; 109: 399-404.

24. Mihaylova MM, Shaw RJ. The AMPK signalling pathway coordinates cell growth autophagy and metabolism. Nat Cell Biol 2011; 13: 1016-1023.

25. Luo Z, Zang M, Guo W. AMPK as a metabolic tumor suppressor: control of metabolism and cell growth. Future Oncol 2010; 6: 457-470.

26. Kawano K, Ikeda Y, Handa M, Kamata T, Anbo H, Araki $Y$ et al. Enhancing effect by heparin on shear-induced platelet aggregation. Semin Thromb Hemost 1990; 16(Suppl): $60-65$

27. Laderoute KR, Amin K, Calaoagan JM, Knapp M, Le T, Orduna J et al. 5'-AMP-activated protein kinase (AMPK) is induced by low-oxygen and glucose deprivation conditions found in solid-tumor microenvironments. Mol Cell Biol 2006; 26: 5336-5347.

28. Hardie DG, Ross FA, Hawley SA. AMPK: a nutrient and energy sensor that maintains energy homeostasis. Nat Rev Mol Cell Biol 2012; 13: 251-262.

29. Munoz-Pinedo C, El Mijyad N, Ricci JE. Cancer metabolism: current perspectives and future directions. Cell Death Dis 2012; 3: e248.

30. Choi YK, Park KG. Metabolic roles of AMPK and metformin in cancer cells. Mol Cells 2013 e-pub ahead of print 19 June 2013; doi:10.1007/s10059-013-0169-8.

31. Pimentel GD, Ropelle ER, Rocha GZ, Carvalheira JB. The role of neuronal AMPK as a mediator of nutritional regulation of food intake and energy homeostasis. Metabolism 2013; 62: $171-178$.

32. Zhou G, Myers R, Li Y, Chen Y, Shen X, Fenyk-Melody J et al. Role of AMP-activated protein kinase in mechanism of metformin action. $J$ Clin Invest 2001; 108: 1167-1174.

33. Jin Q, Feng L, Behrens C, Bekele BN, Wistuba II, Hong WK et al. Implication of AMP. activated protein kinase and Akt-regulated survivin in lung cancer chemopreventive activities of deguelin. Cancer Res 2007; 67: 11630-11639.

34. Park HU, Suy S, Danner M, Dailey V, Zhang Y, Li H et al. AMP-activated protein kinase promotes human prostate cancer cell growth and survival. Mol Cancer Ther 2009; 8: 733-741.

35. Xu ZX, Liang J, Haridas V, Gaikwad A, Connolly FP, Mills GB et al. A plant triterpenoid, avicin $D$, induces autophagy by activation of AMP-activated protein kinase. Cell Death Differ 2007; 14: 1948-1957.

36. Zhou W, Han WF, Landree LE, Thupari JN, Pinn ML, Bililign T et al. Fatty acid synthase inhibition activates AMP-activated protein kinase in SKOV3 human ovarian cancer cells. Cancer Res 2007; 67: 2964-2971.

37. Langelueddecke C, Jakab M, Ketterl N, Lehner L, Hufnagl C, Schmidt S et al. Effect of the AMP-kinase modulators AICAR, metformin and compound $C$ on insulin secretion of INS-1E rat insulinoma cells under standard cell culture conditions. Cell Physiol Biochem 2012; 29 $75-86$

38. Hsu YC, Meng X, Ou L, Ip MM. Activation of the AMP-activated protein kinase-p38 MAP kinase pathway mediates apoptosis induced by conjugated linoleic acid in p53-mutan mouse mammary tumor cells. Cell Signal 2010; 22: 590-599.

39. Baumann P, Mandl-Weber S, Emmerich B, Straka C, Schmidmaier R. Inhibition of adenosine monophosphate-activated protein kinase induces apoptosis in multiple myeloma cells. Anticancer Drugs 2007; 18: 405-410.

40. Jin J, Mullen TD, Hou Q, Bielawski J, Bielawska A, Zhang X et al. AMPK inhibitor Compound $\mathrm{C}$ stimulates ceramide production and promotes Bax redistribution and apoptosis in MCF7 breast carcinoma cells. J Lipid Res 2009; 50: 2389-2397.

41. Vucicevic L, Misirkic M, Janjetovic K, Harhaji-Trajkovic L, Prica M, Stevanovic D et al. AMP-activated protein kinase-dependent and -independent mechanisms underlying in vitro antiglioma action of compound C. Biochem Pharmacol 2009; 77: 1684-1693.
42. Huang SW, Wu CY, Wang YT, Kao JK, Lin CC, Chang CC et al. p53 modulates the AMPK inhibitor compound $\mathrm{C}$ induced apoptosis in human skin cancer cells. Toxicol Appl Pharmacol 2013; 267: 113-124.

43. Yang WL, Perillo W, Liou D, Marambaud P, Wang P. AMPK inhibitor compound C suppresses cell proliferation by induction of apoptosis and autophagy in human colorectal cancer cells. J Surg Oncol 2012; 106: 680-688.

44. Lai $E$, Teodoro $T$, Volchuk $A$. Endoplasmic reticulum stress: signaling the unfolded protein response. Physiology 2007; 22: 193-201.

45. Hsiao JR, Chang KC, Chen CW, Wu SY, Su IJ, Hsu MC et al. Endoplasmic reticulum stress triggers XBP-1-mediated up-regulation of an EBV oncoprotein in nasopharyngeal carcinoma. Cancer Res 2009; 69: 4461-4467.

46. Ron D, Walter P. Signal integration in the endoplasmic reticulum unfolded protein response. Nat Rev Mol Cell Biol 2007; 8: 519-529.

47. Arima Y, Nitta M, Kuninaka S, Zhang D, Fujiwara T, Taya Y et al. Transcriptional blockade induces p53-dependent apoptosis associated with translocation of p53 to mitochondria. J Biol Chem 2005; 280: 19166-19176.

48. Demidenko ZN, Blagosklonny MV. Flavopiridol induces p53 via initial inhibition of Mdm2 and p21 and, independently of p53, sensitizes apoptosis-reluctant cells to tumor necrosis factor. Cancer Res 2004; 64: 3653-3660.

49. Lu W, Chen L, Peng Y, Chen J. Activation of $p 53$ by roscovitine-mediated suppression of MDM2 expression. Oncogene 2001; 20: 3206-3216.

50. Yu J, Zhang L. The transcriptional targets of p53 in apoptosis control. Biochem Biophys Res Commun 2005; 331: 851-858.

51. Sun XM, Bratton SB, Butterworth M, MacFarlane M, Cohen GM. Bcl-2 and Bcl-xL inhibit CD95-mediated apoptosis by preventing mitochondrial release of Smac/DIABLO and subsequent inactivation of X-linked inhibitor-of-apoptosis protein. J Biol Chem 2002; 277: 11345-11351.

52. Adams JM, Cory S. The Bcl-2 protein family: arbiters of cell survival. Science 1998; $\mathbf{2 8 1}$ 1322-1326.

53. Murphy KM, Ranganathan V, Farnsworth ML, Kavallaris M, Lock RB. Bcl-2 inhibits Bax translocation from cytosol to mitochondria during drug-induced apoptosis of human tumor cells. Cell Death Differ 2000; 7: 102-111.

54. Sassone J, Maraschi A, Sassone F, Silani V, Ciammola A. Defining the role of the Bcl-2 family proteins in Huntington's disease. Cell Death Dis 2013; 4: e772.

55. Wek RC, Jiang HY, Anthony TG. Coping with stress: elF2 kinases and translational control. Biochem Soc Trans 2006; 34(Pt 1): 7-11.

56. Vucicevic L, Misirkic M, Janjetovic K, Vilimanovich U, Sudar E, Isenovic E et al. Compound $\mathrm{C}$ induces protective autophagy in cancer cells through AMPK inhibition-independent blockade of Akt/mTOR pathway. Autophagy 2011; 7: 40-50.

57. Saito S, Furuno A, Sakurai J, Park HR, Shin-ya K, Tomida A. Compound C prevents the unfolded protein response during glucose deprivation through a mechanism independent of AMPK and BMP signaling. PLoS One 2012; 7: e45845.

58. te Poele RH, Okorokov AL, Joel SP. RNA synthesis block by 5, 6-dichloro-1-beta-Dribofuranosylbenzimidazole (DRB) triggers p53-dependent apoptosis in human colon carcinoma cells. Oncogene 1999; 18: 5765-5772.

59. Dai R, Li J, Fu J, Chen Y, Yu L, Zhao X et al. Disturbance of Ca2 + homeostasis converts pro-Met into non-canonical tyrosine kinase p190MetNC in response to endoplasmic reticulum stress in MHCC97 cells. J Biol Chem 2012; 287: 14586-14597.

60. Dai R, Li J, Fu J, Chen Y, Wang R, Zhao X et al. The tyrosine kinase c-Met contributes to the pro-tumorigenic function of the $\mathrm{p} 38$ kinase in human bile duct cholangiocarcinoma cells. J Biol Chem 2012; 287: 39812-39823.
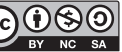

Cell Death and Disease is an open-access journal published by Nature Publishing Group. This work is licensed under a Creative Commons Attribution-NonCommercialShareAlike 3.0 Unported License. To view a copy of this license, visit http://creativecommons.org/licenses/by-nc-sa/3.0/

Supplementary Information accompanies this paper on Cell Death and Disease website (http://www.nature.com/cddis) 